Supplement of The Cryosphere, 11, 2439-2462, 2017

https://doi.org/10.5194/tc-11-2439-2017-supplement

(C) Author(s) 2017. This work is distributed under

the Creative Commons Attribution 3.0 License.

(c) (1)

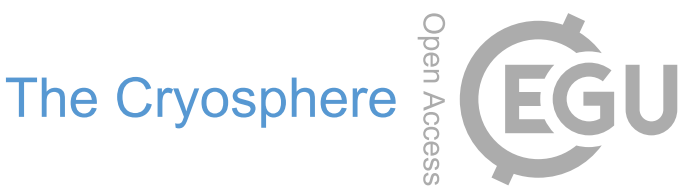

Supplement of

\title{
Methanesulfonic acid (MSA) migration in polar ice: data synthesis and theory
}

Matthew Osman et al.

Correspondence to: Matthew Osman (osmanm@mit.edu)

The copyright of individual parts of the supplement might differ from the CC BY 3.0 License. 


\section{S1: Defining the shallowest depth of MSA migration, with emphasis on the Greenland sites D4 and Summit2010}

In this section, we provide further details about how the shallowest depth at which MSA occurs $\left(z_{f o}\right)$ is determined in this study. Such a determination involves some subjectivity. As noted in the main text (Section 2), we broadly define $z_{f o}$ as the depth where [MS-] shows its annual peak within a winter layer. This definition appears consistent with previous descriptions of the phenomenon, i.e., the loss of clear summer $\left[\mathrm{MS}^{-}\right]$maxima and depressed annual $\left[\mathrm{MS}^{-}\right]$amplitudes relative to those in the shallow portion of the core (Mulvaney et al., 1992; Pasteur and Mulvaney, 2000; Curran et al., 2002). In all but five of the sites considered in our compilation (Table 1), we use values of $z_{f o}$ as reported in prior studies. At two sites (Dolleman Island sites (1) and (2)), we redefine the values of $z_{f o}$ from those suggested in the original publications (Pasteur and Mulvaney, 2000) to be consistent within our broader definition (Table S1). At the three remaining sites - DIV2010, and the Greenland sites D4 and Summit2010 - no prior estimate of $z_{f o}$ appears to be available in the literature. Details on the determination of $z_{f o}$ in DIV2010 are provided in the main text; below we clarify the criteria used to define $z_{f o}$ at both D4 and Summit2010.

At both D4 and Summit2010, MSA migration appears progressive down-core. As such, for the purposes of our study, $z_{f o}$ is defined at each site by calculating monthly averages of [MS'] for each decade all along the core. The monthly $\left[\mathrm{MS}^{-}\right]$averages are normalized so as to range from 0 to 1 , and the month of maximum [MS-] (=1) for each decade is recorded. We assume that the youngest (shallowest) decade contains the "true" (i.e., unaffected by migration) month of maximum [MS']. Hence, we define $z_{f o}$ at both sites as the shallowest depth where the month of the annual [MS'] maximum differs from the "true" month of maximum [MS'] by more than 3 months. The results are provided in Table S1, and illustrated in Figures S2 and S3 for D4 and Summit2010, respectively.

\section{S2. Calculation of the Slopes of the Liquidus Curves}

The slope of the liquidus curve, $\Gamma$, as introduced in Rempel et al. (2002), approximates the dependence of super-cooling on the mass fraction (wt \%) of a given impurity species dissolved in $\mathrm{H}_{2} \mathrm{O}$ (Figure S4), such that

$\Gamma_{i} \approx \frac{T_{m}-T}{c_{i}}$. 
Here, $T_{m}$ is the melting point of pure water $(273.15 \mathrm{~K}), T$ is the temperature at the eutectic point, and $c_{i}$ is the intergranular concentration of species $i$ at the eutectic point $\left(\mathrm{mol} \mathrm{L}^{-1}\right)$. The liquidus curve slope is calculated here by linearly interpolating between the eutectic composition (see Table 2 and references therein) and zero mass fraction $\left(\mathrm{H}_{2} \mathrm{O}=100 \mathrm{wt} \%\right.$ ) (Figure $\left.\mathrm{S} 4\right)$. We note that alternative approaches, e.g. a linear regression of all data between these two points, are possible. As noted by Rempel et al. (2002), the values of $\Gamma_{i}$ are typically most similar between impurity species when the concentration of the solute is expressed in units of molarity $\left(\mathrm{mol} \mathrm{L}^{-1}\right)$.

To illustrate how the $\Gamma$ values reported in Table 2 are calculated, we provide an example below using the $\mathrm{NaCl}-\mathrm{H}_{2} \mathrm{O}$ binary system. For this system, the eutectic point is characterized by a solution containing $23.3 \% \mathrm{NaCl}$ by mass $\left(76.7 \% \mathrm{H}_{2} \mathrm{O}\right)$ and a temperature of $-21.3^{\circ} \mathrm{C}(251.85 \mathrm{~K})$. The molarity of $\mathrm{NaCl}$ in the solution at the eutectic point, $C_{\mathrm{NaCl}}$, is

$c_{N a C l}=\frac{m_{N a C l} \cdot \rho_{\mathrm{NaCl}}}{M_{\mathrm{NaCl}}}$,

where $m_{\mathrm{NaCl}}=0.233$ is the mass fraction ( $23.3 \mathrm{~g} \mathrm{NaCl}$ per $100 \mathrm{~g} \mathrm{NaCl}-\mathrm{H}_{2} \mathrm{O}$ solution), $M_{\mathrm{NaCl}}=58.44 \mathrm{~g}$ $\mathrm{NaCl} \mathrm{mol}{ }^{-1}$ is the molar mass of $\mathrm{NaCl}$, and $\rho_{\mathrm{NaCl}}=1160 \mathrm{~g} \mathrm{NaCl}^{-} \mathrm{H}_{2} \mathrm{O} \mathrm{L}^{-1}$ is the density of the $\mathrm{NaCl}-\mathrm{H}_{2} \mathrm{O}$ solution at the eutectic composition, such that $c_{\mathrm{NaCl}}=4.6 \mathrm{~mol} \mathrm{NaCl} \mathrm{L}^{-1}$. Thus, by eq. (S1),

$\Gamma_{\mathrm{NaCl}}=\frac{T_{m}-T}{c_{\mathrm{NaCl}}}=\frac{(273.15-251.85) K}{(4.6) \mathrm{M}}=4.6 \frac{\mathrm{K}}{\mathrm{M}}$.

\section{S3. Discretization of the MSA migration models}

\section{S3.1. Linearized model}

Equation (13) is solved numerically using finite differences. The model grid is staggered, with $c_{M S}$ defined at equally spaced points and the effective velocity $w_{*}$ defined at points located midway between the $c_{M S}$-carrier points. Both the upper and lower boundaries of the model domain coincide with $w_{*}$-carrier points. Equation (13) is discretized using an upstream scheme and a centered difference scheme for the diffusion term. With the grid point index $i=1,2, \ldots N$, increasing with depth in the core, the discrete analogue of (13) is 
$\left.\left.c_{i}^{t+1}=c_{i}^{t}-\frac{\Delta t}{\Delta z}\left\{\left(\frac{w_{i+\frac{1}{2}}+w_{i+\frac{1}{2}} \mid}{2}\right) c_{i}^{t}+\left(\frac{w_{i+\frac{1}{2}} \mid w_{i+\frac{1}{2}}}{2}\right) c_{i+1}^{t}\right]-\left[\left(\frac{w_{i-\frac{1}{2}}+w_{i-\frac{1}{2}} \mid}{2}\right) c_{i-1}^{t}+\left(\frac{w_{i-\frac{1}{2}}-\mid w_{i-\frac{1}{2}}}{2}\right) c_{i}^{t}\right]\right\}+\frac{D \Delta t}{(\Delta z)^{2}} \cdot\left(c_{i-1}^{t}-2 c_{i}^{t}+c_{i+1}^{t}\right)\right)$.

Here $c=c_{M S}, w=w_{*}, D=D_{M S}, \Delta t=2.5 \cdot 10^{6} \mathrm{~s}$ ( $\sim 29$ days $)$ is the time step chosen so as to satisfy the CFL criterion, and $\Delta z=0.05 \mathrm{~m}$, corresponding to the sampling interval for the DIV2010 core. The effective velocity $w$ is calculated from the profile of $\bar{c}=\left[\mathrm{Na}^{+}\right]$,

$w_{i+\frac{1}{2}}=\frac{D}{\Delta z} \ln \left(\frac{\overline{c_{l+1}}}{\overline{c_{l}}}\right)$

Equation (S3) can be written in the more compact form

$c_{i}^{t+1}=\alpha_{i} c_{i-1}^{t}+\beta_{i} c_{i}^{t}+\gamma_{i} c_{i+1}^{t}$

where $\alpha_{i}, \beta_{i}$, and $\gamma_{i}$ are dimensionless coefficients given by

$\alpha_{i}=\frac{\Delta t}{\Delta z}\left(\frac{w_{i-\frac{1}{2}}+\left|w_{i-\frac{1}{2}}\right|}{2}\right)+\frac{D \Delta t}{(\Delta z)^{2}}$

$\beta_{i}=1-\frac{\Delta t}{\Delta z}\left(\frac{w_{i+\frac{1}{2}}+\left|w_{i+\frac{1}{2}}\right|}{2}\right)+\frac{\Delta t}{\Delta z}\left(\frac{w_{i-\frac{1}{2}}-\left|w_{i-\frac{1}{2}}\right|}{2}\right)-2 \frac{D \Delta t}{(\Delta z)^{2}}$

$\gamma_{i}=-\frac{\Delta t}{\Delta z}\left(\frac{w_{i+\frac{1}{2}}-\left|w_{i+\frac{1}{2}}\right|}{2}\right)+\frac{D \Delta t}{(\Delta z)^{2}}$

Equation (S5) is used to calculate $c$ at the grid points $i=2,3, \ldots, N-1$. For the shallowest grid point $(i=$ 1), the following equation is used,

$c_{1}^{t+1}=\beta_{1} c_{1}^{t}+\gamma_{1} c_{2}^{t}$

(S7),

which implicitly satisfies the condition of no $c$ flux at the upper boundary. Likewise, at the deepest grid point $(i=N)$, the following equation is used, 
$c_{N}^{t+1}=\alpha_{N} c_{N-1}^{t}+\beta_{N} c_{N}^{t}$

which implicitly satisfies the condition of no $c$ flux at the lower boundary.

\section{S3.2. Model of Rempel et al. (2002)}

The method of solution of the RWW model follows largely that for the linearized model. Equations (6a-b) are solved using finite differences and a staggered grid. The concentrations of $\mathrm{MS}^{-}$and $\mathrm{Na}^{+}, c_{M S}$ and $c_{N a}$, are defined at equally spaced points, and the effective velocity $w_{*}$ is defined at points located midway between the concentration-carrier points. The upper and lower boundaries of the model domain coincide with $w_{*}$-carrier points. The discrete analogue of equation (6a) is,

$c_{M S, i}^{t+1}=$

$c_{M S, i}^{t}-\frac{\Delta t}{\Delta z}\left[\left(\frac{w_{M S, i+\frac{1}{2}}^{t}+w_{M S, i+\frac{1}{2}}^{t} \mid}{2}\right) c_{M S, i}^{t}+\left(\frac{w_{M S, i+\frac{1}{2}}^{t}\left|w_{M S, i+\frac{1}{2}}^{t}\right|}{2}\right) c_{M S, i+1}^{t}\right]-\frac{\Delta t}{\Delta z}\left[\left(\frac{w_{M S, i-\frac{1}{2}}^{t}+\left|w_{M S, i-\frac{1}{2}}^{t}\right|}{2}\right) c_{M S, i-1}^{t}+\left(\frac{w_{M S, i-\frac{1}{2}}^{t}-\left|w_{M S, i-\frac{1}{2}}^{t}\right|}{2}\right) c_{M S, i}^{t}\right]$,

(S9)

where

$w_{M S, i+\frac{1}{2}}^{t}=\left(D_{M S} \frac{\Gamma_{N a}}{\Gamma_{M S} \cdot c_{M S, i+\frac{1}{2}}^{t}+\Gamma_{N a} \cdot c_{N a, i+\frac{1}{2}}^{t}} \cdot\left[\frac{c_{N a, i+1}^{t}-c_{N a, i}^{t}}{\Delta z}-\frac{c_{N a, i+\frac{1}{2}}^{t}}{c_{M S, i+\frac{1}{2}}^{t}} \cdot \frac{c_{M S, i+1}^{t}-c_{M S, i}^{t}}{\Delta z}\right]\right)$

$w_{M S, i-\frac{1}{2}}^{t}=\left(D_{M S} \frac{\Gamma_{N a}}{\Gamma_{M S} \cdot c_{M S, i-\frac{1}{2}}^{t}+\Gamma_{N a \cdot c}^{t} c_{N a, i-\frac{1}{2}}} \cdot\left[\frac{c_{N a, i}^{t}-c_{N a, i-1}^{t}}{\Delta z}-\frac{c_{N a, i-\frac{1}{2}}^{t}}{c_{M S, i-\frac{1}{2}}^{t}} \cdot \frac{c_{M S, i}^{t}-c_{M S, i-1}^{t}}{\Delta z}\right]\right)$

Expressions similar to (S9-10) are used for equation (6b). Note that the ionic concentrations at the $w_{*}$ carrier points are obtained by linear interpolation from the two neighboring values. As for the linearized model, $\Delta t$ is set to $2.5 \cdot 10^{6} \mathrm{~s}$ ( $\sim 29$ days $)$ and $\Delta z$ is set equal to $0.05 \mathrm{~m}$.

At the upper and lower boundaries, a condition of no flux is prescribed for both ions. Thus, at the grid point nearest to the upper boundary, the concentration of $\mathrm{MS}^{-}$is computed from

$c_{M S, 1}^{t+1}=c_{M S, 1}^{t}-\frac{\Delta t}{\Delta z}\left[\left(\frac{w_{M S, \frac{3}{2}}^{t}\left|w_{M S, \frac{3}{2}}^{t}\right|}{2}\right) c_{M S, 1}^{t}+\left(\frac{w_{M S, \frac{3}{2}}^{t}-\left|w_{M S, \frac{3}{2}}^{t}\right|}{2}\right) c_{M S, 2}^{t}\right]$, 
where

$w_{M S, \frac{3}{2}}^{t}=\left(D_{M S} \frac{\Gamma_{N a}}{\Gamma_{M S \cdot c_{M S, \frac{3}{2}}^{t}+\Gamma_{N a} \cdot c_{N a, \frac{3}{2}}^{t}}} \cdot\left[\frac{c_{N a, 2}^{t}-c_{N a, 1}^{t}}{\Delta z}-\frac{c_{N a, \frac{3}{2}}^{t}}{c_{M S, \frac{3}{2}}^{t}} \cdot \frac{c_{M S, 2}^{t}-c_{M S, 1}^{t}}{\Delta z}\right]\right)$,

Likewise, the concentration of $\mathrm{MS}^{-}$at the grid point nearest to the lower boundary is computed from

$c_{M S, N}^{t+1}=c_{M S, N}^{t}-\frac{\Delta t}{\Delta z}\left[\left(\frac{w_{M S, N-\frac{1}{2}}^{t}+\mid w_{M S, N-\frac{1}{2}}^{t}}{2}\right) c_{M S, N-1}^{t}+\left(\frac{w_{M S, N-\frac{1}{2}}^{t}\left|w_{M S, N-\frac{1}{2}}^{t}\right|}{2}\right) c_{M S, N}^{t}\right]$,

where

$w_{M S, N-\frac{1}{2}}^{t}=\left(D_{M S} \frac{\Gamma_{N a}}{\Gamma_{M S \cdot c c_{M S, N-\frac{1}{2}}^{t}+\Gamma_{N a} \cdot c_{N a, N-\frac{1}{2}}^{t}}} \cdot\left[\frac{c_{N a, N}^{t}-c_{N a, N-1}^{t}}{\Delta z}-\frac{c_{N a, N-\frac{1}{2}}^{t}}{c_{M S, N-\frac{1}{2}}^{t}} \cdot \frac{c_{M S, N}^{t}-c_{M S, N-1}^{t}}{\Delta z}\right]\right)$,

Equations (S11) and (S13) implicitly satisfy the condition of no flux at the upper boundary and lower boundary, respectively. Expressions similar to (S11-12) and (S13-14) are used to compute the concentration of $\mathrm{Na}^{+}$at grid points nearest to the upper and lower boundaries.

\section{Section S4. Modeling MSA migration at DIV2010}

Simulating the $\left[\mathrm{MS}^{-}\right]$record for DIV2010, as described in Sections 4.4 and 5.2, requires accounting for the variable amplitude of MSA migration along the core. We assume that MSA migration takes place only below a critical depth $z_{\text {crit }}$, which is set equal to $9.1 \mathrm{~m}$ for the DIV2010 core (section 3 ). At depths shallower than $z_{\text {crit }}$ migration is thus assumed not to occur due, e.g., to too low ice densities (section 2.4). From the DIV2010 core chronology, we infer the amount of time migration has occurred at each core depth where [MS$\left.{ }^{-}\right]$has been measured. This time interval is denoted as $\Delta t_{i}$, where subscript $i$ refers to a particular depth level, and calculated from $\Delta t_{i}=a_{i}-a_{c r i t}$, where $a_{i}$ is the calendar age at depth level $i$ and $a_{c r i t}$ is the calendar age at the critical depth. The model domain extends from $z=9.1 \mathrm{~m}$ to $z=60.4 \mathrm{~m}$, and the model grid is set up such that each grid point coincides with a depth where [MS $\left.{ }^{-}\right]$ has been measured, i.e., $i=1,2, \ldots, \mathrm{N}$, where $i=1$ denotes the shallowest grid point and $i=\mathrm{N}$ the 
deepest grid point.

The migration of MSA is then incorporated as follows in the model. The model is integrated over a time interval equal to $\Delta t_{N}=a_{N}-a_{c r i t} \approx 95$ years, which is the estimated time interval during which migration has affected the deepest sample of DIV2010. At each model iteration $n$, where $n=1,2, \ldots$, $\Delta t_{N} / \Delta \mathrm{t}$ and $\Delta \mathrm{t} \approx 0.08 \mathrm{yr}$ is the model time step, the integration time $n \Delta \mathrm{t}$ is compared to the migration time $\Delta t_{i}$ at each grid point. If $\Delta t_{i} \leq \Delta t_{N}-n \Delta \mathrm{t} n$, then migration at the $i$ th grid point is inactivated: the effective velocities $w_{M S}$ and $w_{N a}$ are set to 0 , so that $\left[\mathrm{MS}^{-}\right]$and $\left[\mathrm{Na}^{+}\right]$remain unaltered at this point. Conversely, if $\Delta t_{i}>\Delta t_{N}-n \Delta \mathrm{t}$, then migration at the $i$ th grid point is activated: $w_{M S}$ and $w_{N a}$ are calculated according to equations (7a-b), so that $\left[\mathrm{MS}^{-}\right]$and $\left[\mathrm{Na}^{+}\right]$suffer convergence or divergence at this point. Hence, $\left[\mathrm{MS}^{-}\right]$and $\left[\mathrm{Na}^{+}\right]$at shallow grid points are subjected to transport over a smaller amount of time than $\left[\mathrm{MS}^{-}\right]$and $\left[\mathrm{Na}^{+}\right]$at deeper grid points. In figures S5 and S6, the activation of the migration process at progressively shallower grid points can be visualized by the variable position of the vertical yellow bar, which separates the region where migration is allowed to take place from the region where migration is not allowed to take place in the model domain.

\section{Section S5. Sensitivity Experiments with the RWW Model}

Calculation of a predicted MSA migration time was implemented by creating two idealized and out of phase sinusoidal curves of identical wavelength, $\lambda$, representing an [MS-] annual cycle and an $\left[\mathrm{Na}^{+}\right]$annual cycle. In each test, the model grid comprises the same number of model grid points $(n=$ 101), so that truncation errors due to spatial differencing are of comparable magnitude between experiments. The initial profile of $\left[\mathrm{MS}^{-}\right]$is given by

$\left[M S^{-}\right]=a_{M S} \cdot \sin \left(\frac{2 \pi}{\lambda} z\right)+b_{M S}$

while the initial profile of $\left[\mathrm{Na}^{+}\right]$was additionally varied by a scalar $\overline{N^{+}}$relative to the $\mathrm{MS}^{-}$ concentration,

$\left[N a^{+}\right]=\left(\overline{N a^{+}} \cdot \frac{a_{N a}}{b_{N a}}\right) \cdot \sin \left(\frac{2 \pi}{\lambda} z+\pi\right)+\overline{N a^{+}}$

In our tests, we considered 17 values of $\overline{\mathrm{Na}^{+}}$between 16 and $400 \mu \mathrm{g} \mathrm{L}{ }^{-1}$, and 19 values of $\lambda$ between 0.1 
and $1.0 \mathrm{~m}$, for a total of 323 tests. The coefficients $a_{M S}, b_{M S}, a_{N a}$, and $b_{N a}$ are determined from a least squares fit of equations (S15) and (S16) to the mean monthly profiles of [MS $]$ and $\left[\mathrm{Na}^{+}\right]$observed in the DIV2010 shallow zone (Fig. 8), which yield $a_{M S}=5.1 \mu \mathrm{g} \mathrm{L}^{-1}, b_{M S}=6.2 \mu \mathrm{g} \mathrm{L}^{-1}, a_{N a}=15.0 \mu \mathrm{g} \mathrm{L}^{-1}$, and $b_{N a}=39.2 \mu \mathrm{g} \mathrm{L}{ }^{-1}$. As a result, in our tests, the product $\overline{N a^{+}} \cdot \frac{a_{N a}}{b_{N a}}$ ranges from $\sim 9.6$ and $153.3 \mu \mathrm{g} \mathrm{L}^{-1}$.

\section{Supplementary Figures}
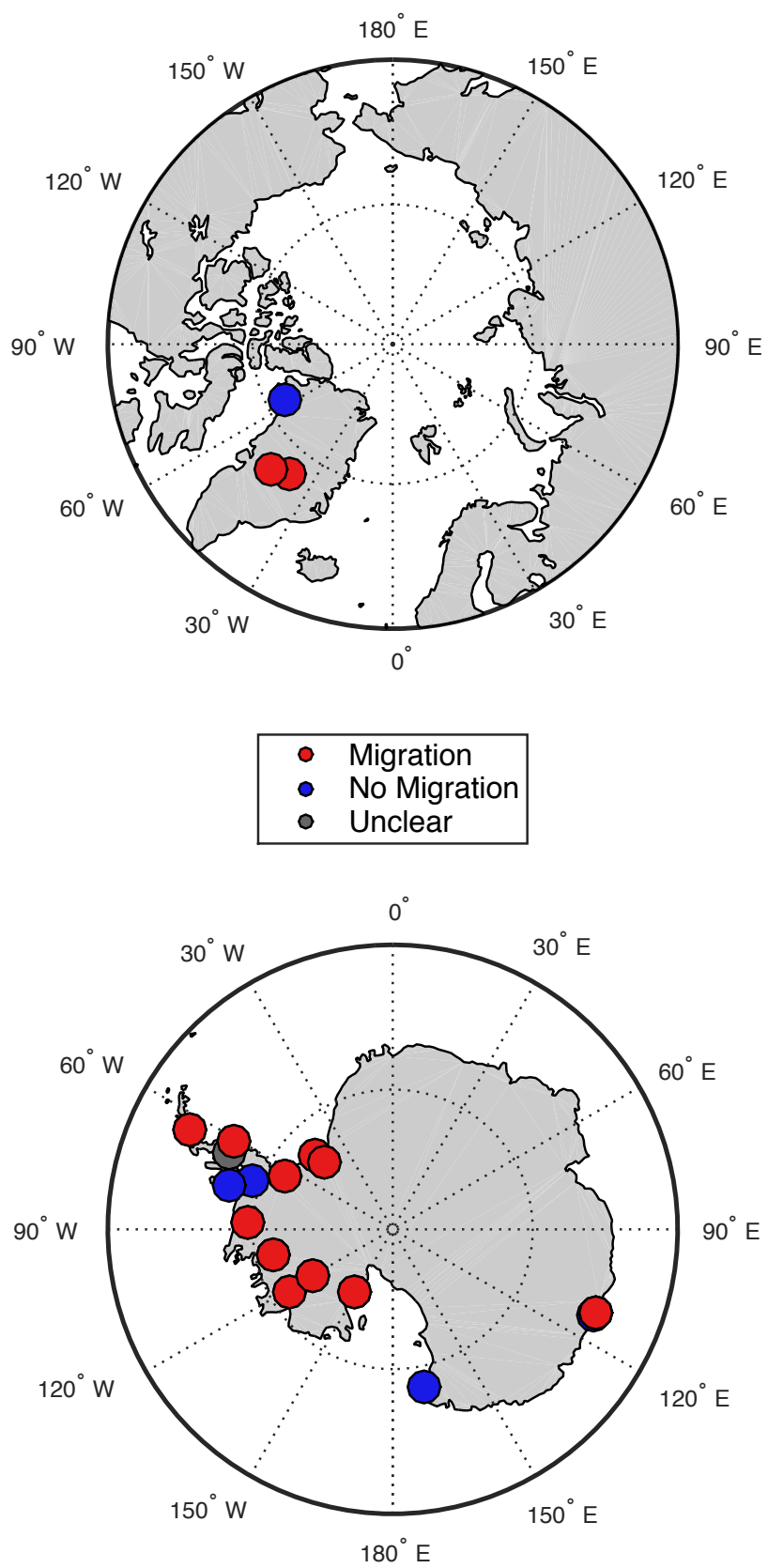
Figure S1: Distribution of the 20 sites considered in this study, located in Greenland (top) and Antarctica (bottom). Note that all three Law Dome sites (DSS, DE08, W20k, all at $\sim 66^{\circ} \mathrm{S}, \sim 113^{\circ} \mathrm{E}$ ) are each within $35 \mathrm{~km}$ of each other (Curran et al., 2002) and that only W20k (where MSA migration was observed) is visible in the map. Not visible are Law Dome DSS, where MSA migration was found to be unclear, and DE08, where MSA migration was not found.

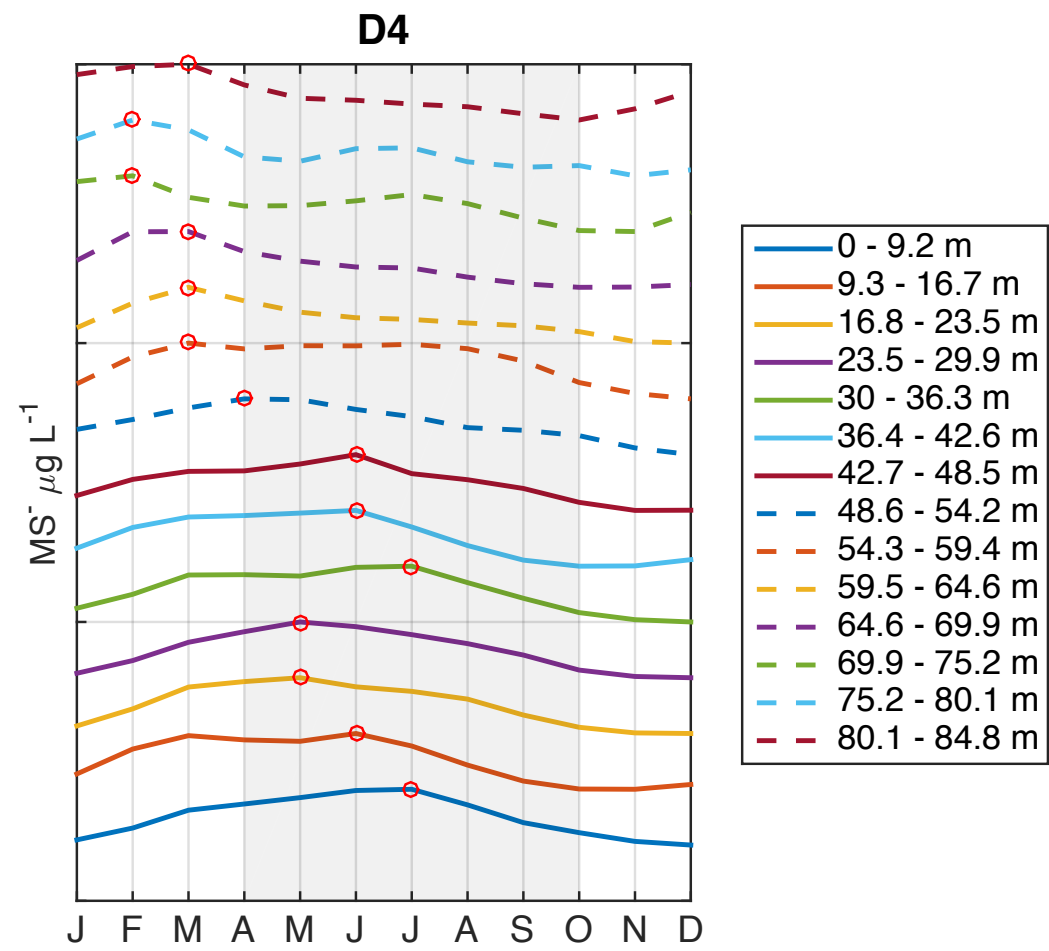

Figure S2: Monthly averages of [MS'] for different decades (corresponding to different depth intervals in the core and different colors in the figure) at the D4 core site, Greenland. The averages are normalized so as to range from 0 to 1 and plotted on top of each other for better visualization. The shallowest depth interval from 0 to $9.2 \mathrm{~m}$ represents the decade from Dec-Jan 2003 to DecJan 1994. All other depth intervals represent older and contiguous decades. The red circle on each curve denotes the month of the annual maximum $\left[\mathrm{MS}^{-}\right]$for the corresponding decade. The grey shaded region represents the \pm 3 month range of the "true" month of annual maximum [MS ${ }^{-}$, taken to be July at D4 (the month of annual maximum [MS ${ }^{-}$for the 0-9.2 $\mathrm{m}$ interval). At D4, $z_{f o}$ is estimated to $54.3-59.4 \mathrm{~m}$, the shallowest depth range where the annual [MS'] maximum peaks in a month outside of the shaded region. 


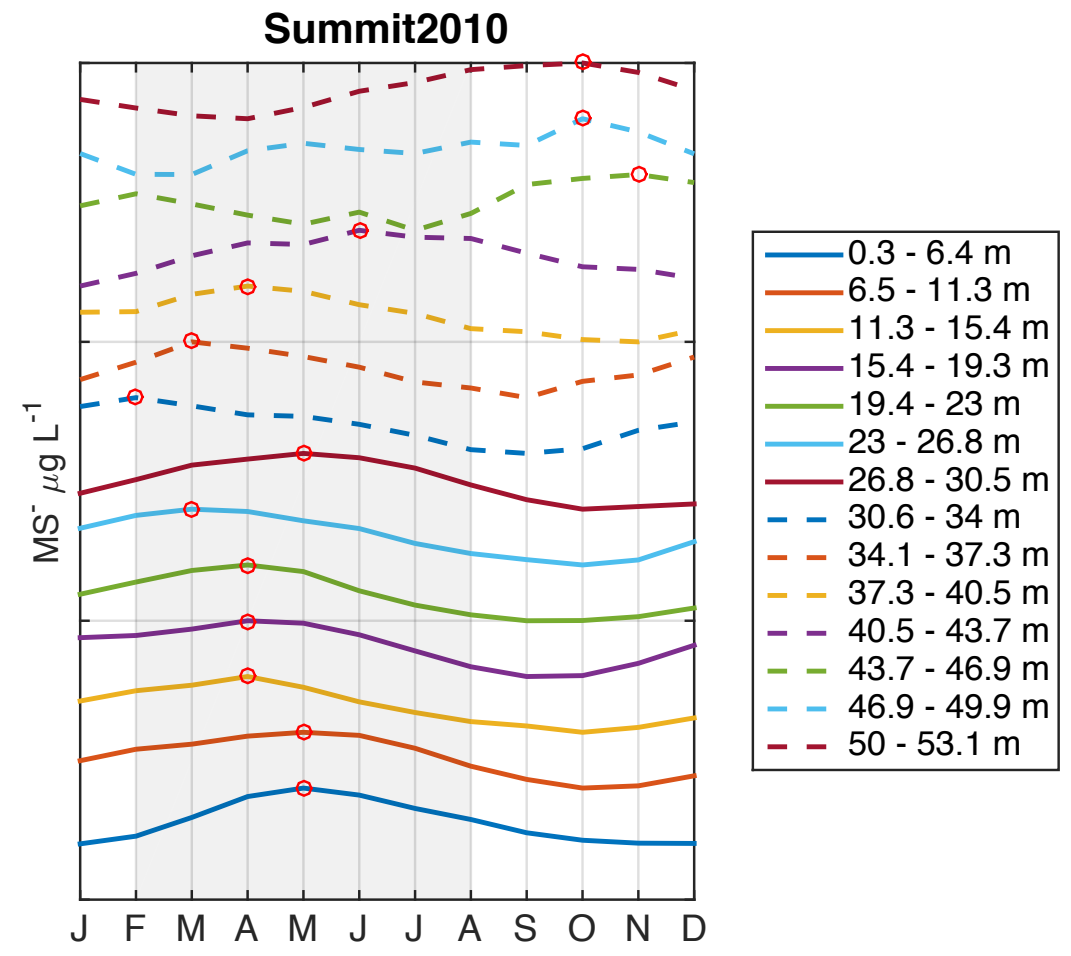

Figure S3: Same as SF2 but for the Summit2010 ice core, Greenland. The shallowest depth interval (0.3-6.4 m) represents the decade from Dec-Jan 2009 to Dec-Jan 2000. The "true" month of annual maximum [MS"] is estimated to be May (the month of annual maximum [MS$\left.{ }^{-}\right]$for the 0.3-6.4 $\mathrm{m}$ interval). At Summit2010, $\mathrm{z}_{f o}$ is estimated to $43.7-46.9 \mathrm{~m}$.

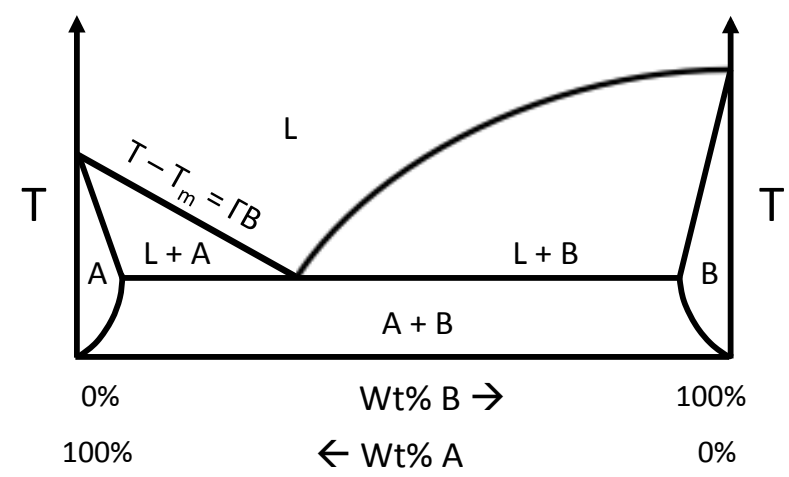


Figure S4: Schematic of a phase diagram for a hypothetical binary mixture. The dependence of super-cooling, $T$ - $T_{m}$, on solute concentration $c$ is approximated by $T-T_{\mathrm{m}}=\Gamma c$, where $\Gamma$, assumed constant, is the slope of the liquidus curve.

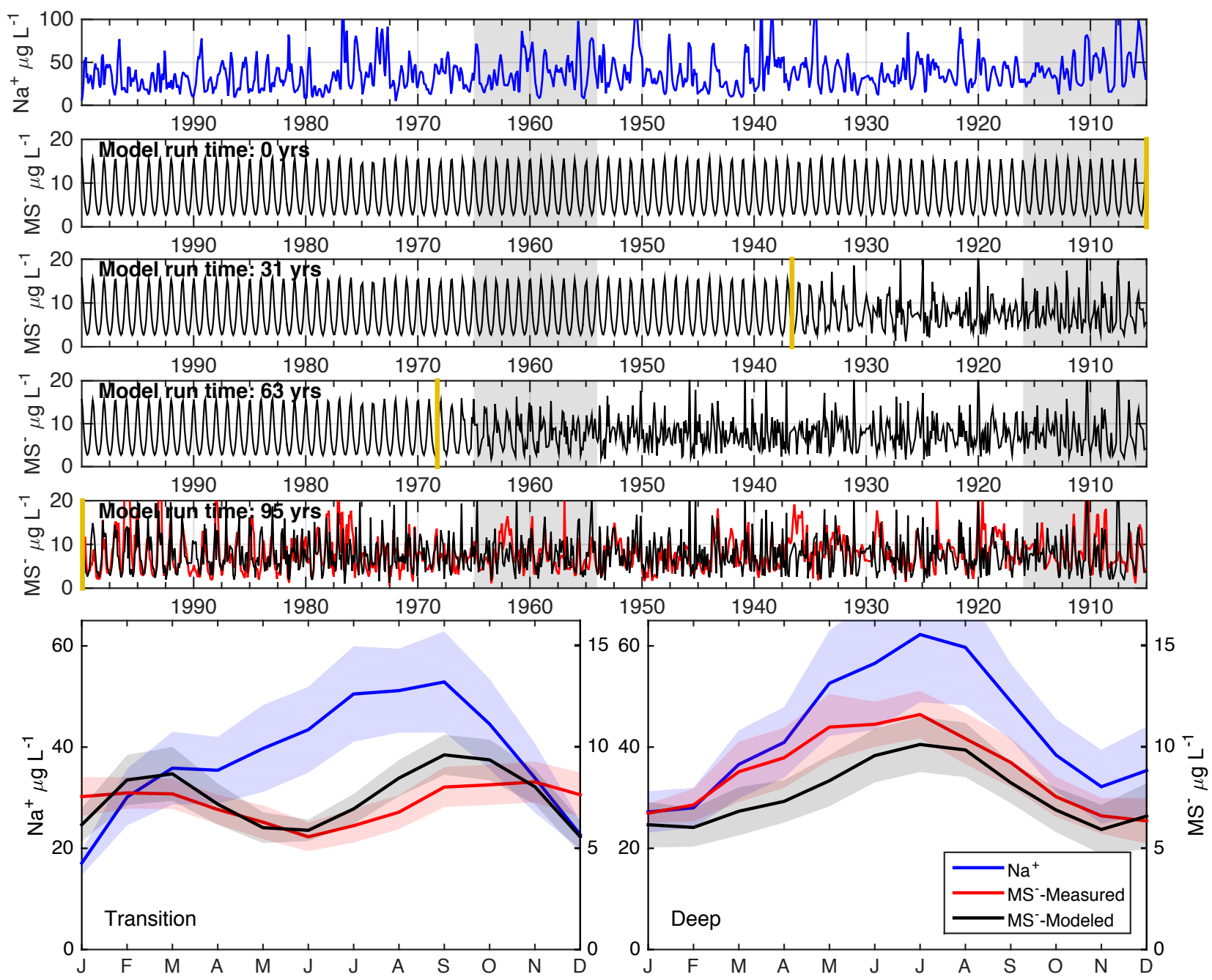

Figure S5: Profiles $\left[\mathrm{Na}^{+}\right]$and $\left[\mathrm{MS}^{-}\right]$measured along the DIV2010 core, and profiles of [MS $]$simulated with the linearized migration model with $D_{M S}=10^{-11} \mathrm{~m}^{2} \mathrm{~s}^{-1}$. Top panel: measured $\left[\mathrm{Na}^{+}\right]$profile (3-pt running average). The shaded bands depict the transition zone (left band) and the deep zone (right band). Middle panels (4 panels): simulated [MS ${ }^{-}$profiles at different times (0, 31, 63, $95 \mathrm{yr}$ ). The shaded bands depict the transition zone (left band) and the deep zone (right band) in DIV2010. The yellow bar separates the region unaffected by migration on the left from the region affected by migration on the right. In the bottommost of the middle panels, the red (black) line shows the measured (simulated) [MS-] profile. Bottom panels (2 panels): monthly mean values of $\left[\mathrm{Na}^{+}\right]$and $\left[\mathrm{MS}^{-}\right]$measured in DIV2010, and monthly mean values of [MS $]$simulated by the model, in the transition zone (left panel) and the deep zone (right panel). In both panels, the shaded regions indicate \pm 1 standard error of the mean. 


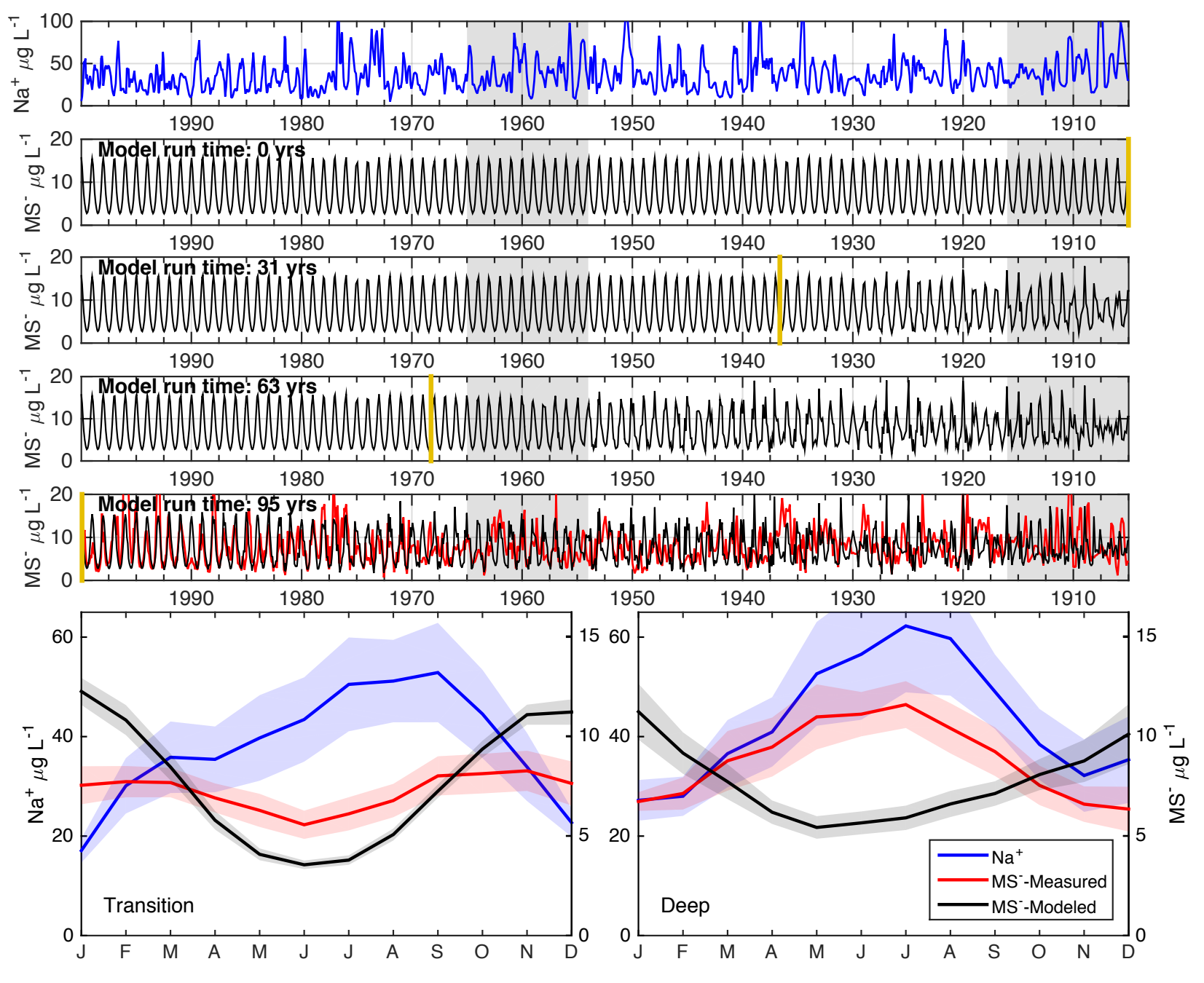

Figure S6: Same as Figure S5, but for $D_{M S}=10^{-12} \mathrm{~m}^{2} \mathrm{~s}^{-1}$. 
Table S1. Notes and references for defining $z_{f o}$

\begin{tabular}{|c|c|c|c|}
\hline Core & $z_{f o}(\mathrm{~m})$ & Notes on defining $Z_{f o}$ & Citation \\
\hline $\begin{array}{l}\text { Dolleman } \\
\text { Island (1) }\end{array}$ & 10 & 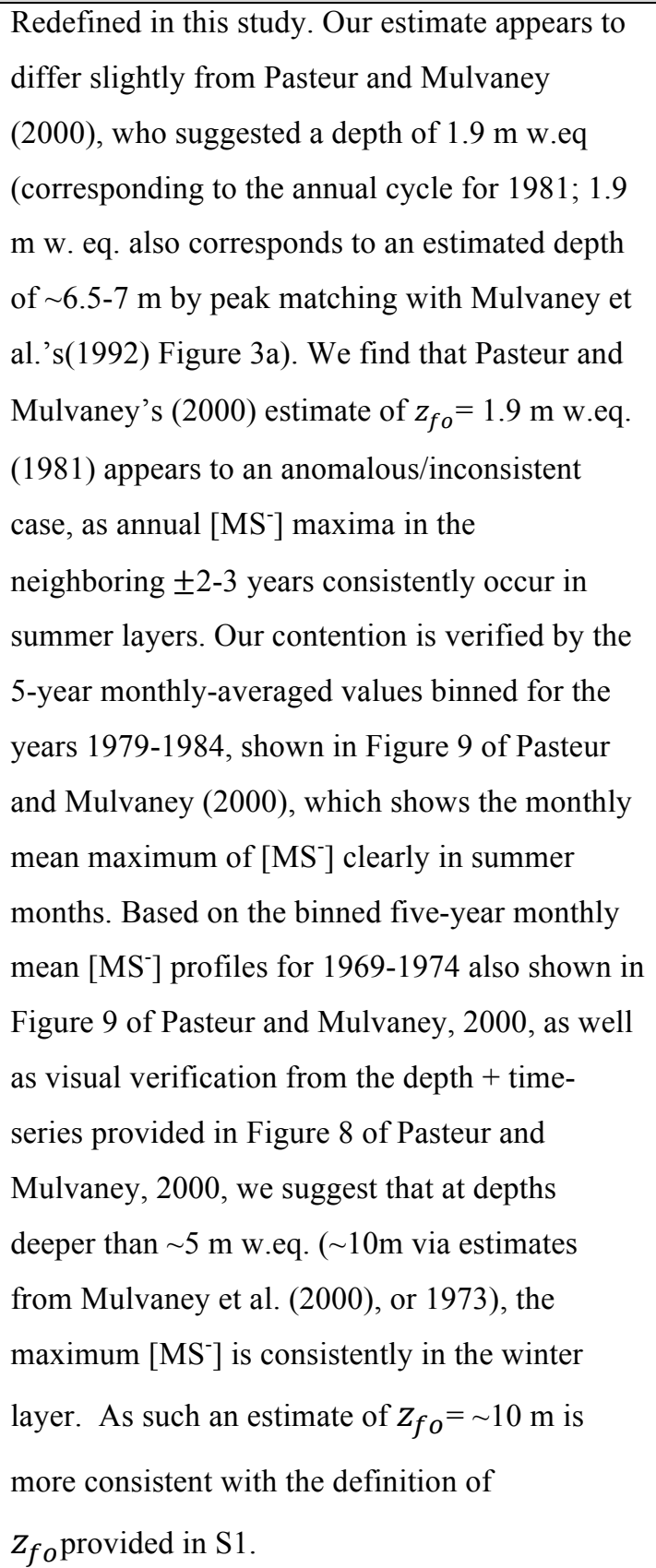 & $\begin{array}{l}\text { Mulvaney et al., 1992; } \\
\text { Pasteur and Mulvaney } 2000\end{array}$ \\
\hline
\end{tabular}




\begin{tabular}{|c|c|c|c|}
\hline $\begin{array}{l}\text { Dolleman } \\
\text { Island (2) }\end{array}$ & $8.5 \mathrm{~m}$ w.eq. & 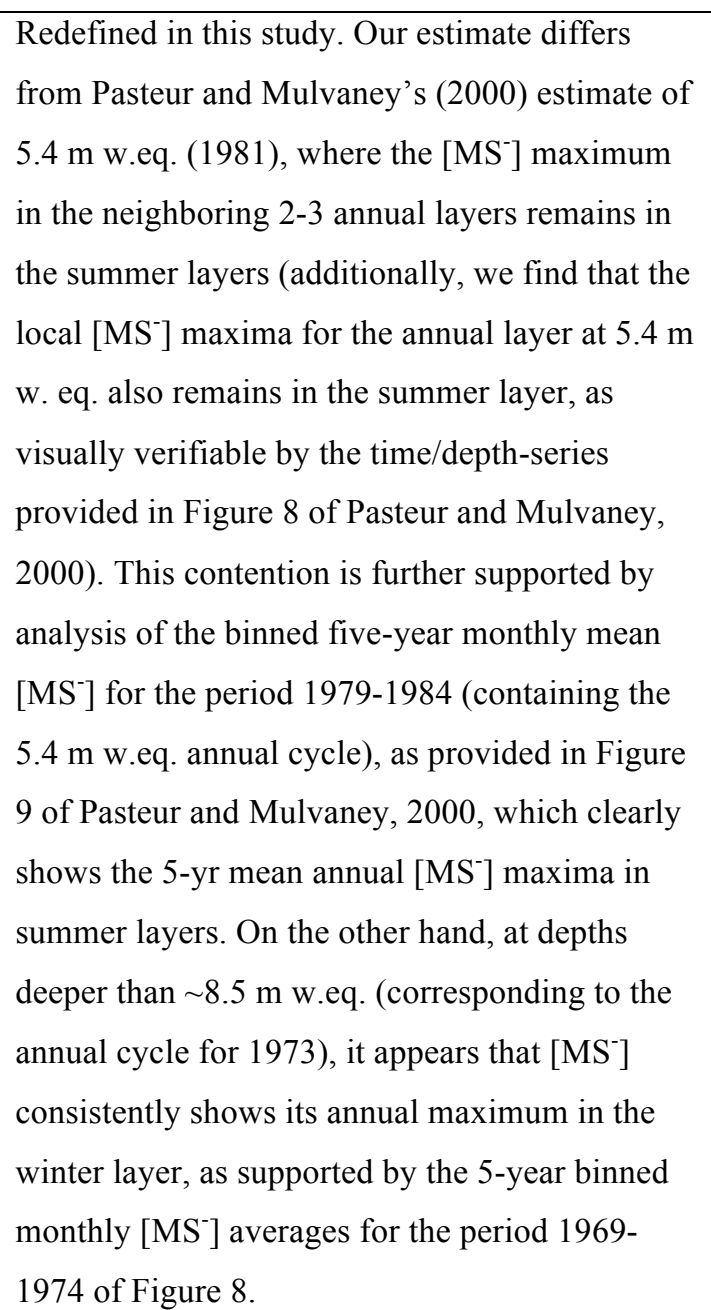 & Pasteur and Mulvaney, 2000 \\
\hline $\begin{array}{l}\text { Berkner Island } \\
\text { North (1) }\end{array}$ & 9 (4.2 m w.eq.) & $\begin{array}{l}\text { Estimate based on Figure } 2 \text { of Wagenbach et al., } \\
1994 \text { (available in depth units of meters of water } \\
\text { equivalent), and supporting data available online } \\
\text { (where data is available in depth units of meters): } \\
\text { https://doi.pangaea.de/10.1594/PANGAEA.5486 } \\
\underline{53} \text {. At depths greater than } 9 \text { m ( } 4.2 \text { m w.eq.; Fig } \\
2 \text { of Wagenbach et al., 1994), MSA annual } \\
\text { maxima clearly switch from being consistently in } \\
\text { summer to consistently in winter. }\end{array}$ & Wagenbach et al., 1994 \\
\hline
\end{tabular}




\begin{tabular}{|c|c|c|c|}
\hline $\begin{array}{l}\text { Berkner Island } \\
\text { South }\end{array}$ & 6 (2.8 m w.eq.) & 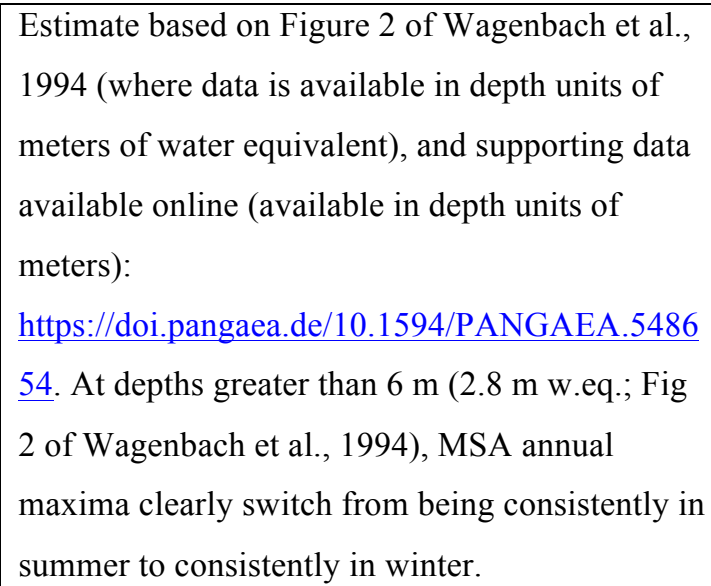 & Wagenbach et al., 1994 \\
\hline DIV2010 & $26 \pm 3$ & $\begin{array}{l}\text { Defined in this study; although the phasing of } \\
\text { maximum annual [MS'] at DIV2010 appears to } \\
\text { be progressive (Fig. } 6 \text { of this study), a } \\
\text { conspicuous and distinctive shift in the seasonal } \\
\text { integrity of the annual [MS'] cycle, and a } \\
\text { corresponding shift towards winter phasing of } \\
\text { [MS'] first becomes prominent at } \sim 26+/-3 \mathrm{~m} \\
\text { depth, as also noted by Criscitiello, } 2014 \text {. }\end{array}$ & $\begin{array}{l}\text { This study; see also } \\
\text { Criscitiello, } 2014\end{array}$ \\
\hline THW2010 & $17 \pm 3$ & $\begin{array}{l}\text { Defined by Criscitiello, 2014; below } \sim 17 \mathrm{~m}, \\
{\left[\mathrm{MS}^{-}\right] \text {peaks near-consistently in winter layers. }}\end{array}$ & Criscitiello, 2014 \\
\hline Bruce Plateau & 395 & $\begin{array}{l}\text { As reported in the supplementary material of } \\
\text { Porter et al., 2016. [MS'] migration onset } \\
\text { appears first apparent at } \sim 380 \mathrm{~m} \text {, and prominent } \\
\text { winter-layer maxima occur by depths of } 395 \mathrm{~m} \text {. }\end{array}$ & Porter et al., 2016 \\
\hline NBY-2 (Byrd) & 2.6 & As reported by Langway et al., 1994 & Langway et al., 1994 \\
\hline $\begin{array}{l}\text { 94-1 Siple } \\
\text { Dome }\end{array}$ & 2 & $\begin{array}{l}\text { As reported by Kreutz et al., 1998; see Kreutz et } \\
\text { al., Figures } 2 \text { and } 3\end{array}$ & Kreutz et al., 1998 \\
\hline $\begin{array}{l}\text { D235: Filchner } \\
\text { Ronne Ice } \\
\text { Shelf }\end{array}$ & $\begin{array}{l}1.8 \mathrm{~m} \text { w.eq. }(3-4 \mathrm{~m} ; \mu \\
=3.5)\end{array}$ & $\begin{array}{l}\text { As reported (in the abstract) of Minikin et al., } \\
\text { 1994. Can be visually verified in Fig. } 2 \text { of } \\
\text { Minikin et al., 1994, where below } 1.8 \text { m w.eq. } \\
\text { [MS }{ }^{-} \text {is consistently peaking in winter layers. }\end{array}$ & Minikin et al., 1994 \\
\hline Ferrigno & 25 & $\begin{array}{l}\text { As reported by Thomas and Abram, } 2016 \text { (see } \\
\text { also Thomas and Abram, } 2016 \text { Supporting } \\
\text { Information) }\end{array}$ & Thomas and Abram, 2016 \\
\hline Summit2010 & $43.7-46.9(\mu=45.3)$ & $\begin{array}{l}\text { Defined in this study; See section S1 and Figure } \\
\text { SF3. }\end{array}$ & $\begin{array}{l}\text { Maselli et al., } 2017 \text { and J. } \\
\text { McConnell (DRI) pers. } \\
\text { comm. }\end{array}$ \\
\hline
\end{tabular}




\begin{tabular}{|l|l|l|l|}
\hline D4 & $54.3-59.4(\mu=56.9)$ & $\begin{array}{l}\text { Defined in this study. See section S1 and Figure } \\
\text { SF2. }\end{array}$ & $\begin{array}{l}\text { J. McConnell (DRI) pers. } \\
\text { comm. }\end{array}$ \\
\hline
\end{tabular}

\section{References}

Criscitiello, A. S. Amundsen Sea sea-ice variability, atmospheric circulation, and spatial variations in snow isotopic composition from new West Antarctic firn cores. Ph.D. Thesis. The Massachusetts Institute of Technology - Woods Hole Oceanographic Institution Joint Program in Oceanography/Applied Science and Engineering, 2014.

Kreutz, K. J., Mayewski, P. A., Whitlow, S. I., and Twickler, M. S., Limited migration of soluble ionic species in a Siple Dome, Antarctica, ice core, Ann. Glaciol., 27, 371-377, 1998.

Langway, C.C., Jr., Osada, K., Clausen, H. B., Hammer, C.U, Shoji, H., and Mitani, A, New chemical stratigraphy over the last millennium for Byrd Station, Antarctica, Tellus, 46B, 40-51, 1994.

Maselli, O. J., Chellman, N. J., Grieman, M., Layman, L., McConnell, J. R., Pasteris, D., Rhodes, R. H., Saltzman, E., and Sigl, M., Sea ice and pollution-modulated changes in Greenland ice core methanesulfonate and bromine, Clim. Past., 13, 39-59, doi:10.5194/cp-2016-49, 2017.

Minikin, A., Wagenbach, D., Graf, W., and Kipfstuhl, J., Spatial and seasonal variations of the snow chemistry at the Filchner-Ronne Ice Shelf, Antarctica, 20, 283-290, 1994.

Mulvaney, R., Pasteur, E. C., Peel, D. A., Saltzman, E. S., and Whung, P. Y., The ratio of MSA to non-sea-salt sulphate in Antarctic Peninsula ice cores, Tellus B, 44(4), doi:10.3402/tellusb.v44i4.15457, 1992.

Pasteur, E. C., and Mulvaney, R., Migration of methane sulphonate in Antarctic firn and ice, J. Geophys. Res.,105, 11525-11534, doi:10.1029/2000JD900006, 2000.

Porter, S. E., Parkinson, C. L., and Mosley-Thompson, E., Bellinghausen Sea ice extent recorded in an Antarctic Peninsula ice core, J. Geophys. Res. Atmos., 121, 13886-13900, doi:10.1002/2016JD025626., 2016.

Thomas, E. R., and Abram, N., Ice core reconstruction of sea ice change in the Amundsen-Ross Seas since 1702 AD, Geophys. Res. Lett., doi:10.1002/2016GL068130, 2016.

Wagenbach, D., Graf, W., Minikin, A., Trefzer, U., Kipestuhl, J., Oerter, H., and Blindow, N., Reconnaissance of chemical and isotopic firn properties on top of Berkner Island, Antarctica, Annals of Glaciology, 20, 307-312, 1994. 